\title{
Pendidikan Pecegahan Obesitas Pada Ibu Di Posyandu Desa Jatikalang Kecamatan Prambon - Sidoarjo
}

\author{
Diani Octaviyanti Handajani ${ }^{1}$; Nourma Yunita ${ }^{2}$ \\ ${ }^{1,2}$ Prodi DIV Kebidanan Universitas Muhammadiyah Gresik \\ Email korespondensi : dianiocta190@umg.ac.id
}

\begin{abstract}
Abstrak
Kelebihan berat badan atau obesitas sampai saat ini masih menjadi masalah kesehatan di seluruh dunia, termasuk Indonesia. Obesitas merupakan penyebab tingginya angka morbiditas dan mortalitas di dunia. Berdasarkan data Riset Kesehatan Indonesia tahun 2018 berat badan lebih ( overweight ) pada dewasa $>18$ tahun sebesar 13,6 \%, Obese 21,8\%, dan angka obesitas pada penduduk usia $>18$ tahun di Jawa Timur sendiri sebanyak 27,8\%. Pengabdian masyarakat ini di lakukan di desa jati kalang kecamatan Prambon - Sidoarjo di bawah pengawasan Puskesmas Prambon. Tujuan dari pengabdian masyarakat ini adalah melakukan pemantauan terhadap ibu - ibu yang mengalami obesitas dengan melakukan pemeriksaan berat badan, memberikan penyuluhan tentang obesitas sehingga apabila terjadi kelebihan berat badan atau obesitas maka bisa segera dideteksi secara dini dan dilakukan penanganan segera. Hasil dari kegiatan ini dihadiri sebanyak $78 \mathrm{ibu}-\mathrm{ibu}$ dan di dapatkan sebanyak 38 ibu dengan status berat badan normal dan 40 ibu mengalami kelebihan berat badan. Rencana tindak lanjut diberikan edukasi tentang memantau berat badan ibu - ibu setiap bulan, memberikan penyuluhan penyebab obesitas, bahaya obesitas bagi kesehatan, dan tips mencegah obesitas.
\end{abstract}

Kata Kunci : Pendidikan, Obesitas

\begin{abstract}
Overweight or Obesity is still a health problem throughout the world, including Indonesia. Obesity is a cause of high rates of morbidity and mortality in the world. Based on Indonesian Health Research data in 2018 overweight in adults $>18$ years by $13.6 \%$, Obese $21.8 \%$, and obesity rates in the population aged $>18$ years in East Java alone as much as 27.8\%. This community service is carried out in the teak kalang village of PrambonSidoarjo sub-district under the supervision of the Prambon Community Health Center. The aim of this community service is to monitor obese mothers by conducting a weight check, providing counseling about obesity so that if overweight or obesity occurs, it can be detected early and prompt treatment is taken. The results of this activity were attended by 78 mothers and obtained as many as 38 mothers with normal weight status and 40 mothers overweight. A follow-up plan is given education about monitoring mothers' body weight every month, providing counseling for obesity-related people, the dangers of obesity for health, and tips to prevent obesity.
\end{abstract}

Keywords: Education, Obesity

Jurnal Pengabdian Masyarakat Al-Irsyad Vol. II, No. 1. April 2020 


\section{PENDAHULUAN}

Kelebihan berat badan atau Obesitas sampai saat ini masih menjadi masalah kesehatan di seluruh dunia, termasuk Indonesia. Obesitas merupakan penyebab tingginya angka morbiditas dan mortalitas di dunia. Berdasarkan data Riset Kesehatan Indonesia tahun 2018 berat badan lebih ( overweight) pada dewasa $>18$ tahun sebesar 13,6 \%, Obesitas 21,8 \%, dan angka obesitas pada penduduk usia $>$ 18 tahun di Jawa Timur sendiri sebanyak 27,8 \%. Obesitas akan berdampak pada komplikasi kesehatan bila terus dibiarkan berupa dampak fisik atau psikososial yang timbul dalam jangka pendek maupun jangka panjang, karena masalah obesitas merupakan masalah kompleks dan beragam yang dipengaruhi oleh faktor genetis, biologis, lingkungan dan perilaku, selain itu Faktor perilaku seperti kebiasaan makan yang kurang sehat, makanan cepat saji, kurangnya aktivitas fisik dan gaya hidup berperan secara signifikan terhadap angka kejadian obesitas, selain itu menurut Dirjen Pengendalian Penyakit dan Penyehatan Lingkungan (P2PL) Kementrian Kesehatan RI, mengungkapkan meningkatnya angka obesitas di Indonesia selain dipengaruhi oleh pola hidup tak sehat juga dipengaruhi oleh lingkungan sosialnya, arus urbanisasi, people lifestyle, serta perubahan kultur masyarakat Indonesia disinyalir menjadi penyebab tingginya angka obesitas.

Pendidikan diyakini sebagai pondasi berdirinya suatu negara yang maju dan berkembang. Seluruh masyarakat bertanggungjawab dan memperjuangkan atas pendidikan untuk dirinya serta orang - orang di sekitarnya. Macam pendidikan beragam salah satu yang sangat penting, namun seringkali diabaikan. Pedidikan tentang obesitas juga merupakan salah satu hal yang penting untuk dipelajari dan dipahami, karena tingkat pendidikan seseorang akan mempengaruhi dalam memberi respon terhadap suatu yang datang dari luar. Semakin tinggi tingkat pendidikan maka semakin tinggi kemampuan yang dimiliki, bisa menerima suatu infomasi dengan mudah dibandingkan dengan yang berpendidikan rendah. Sebab pendidikan yang tinggi juga akan mampu memahami realitas yang terjadi di masyarakat dan akan berkontribusi kepada masyarakat disekitarnya (Ali, 2009), dengan pendidikan tinggi maka seseorang akan cenderung untuk mendapatkan informasi, baik dari orang lain maupun media massa (Maidartati dan Parsaulian, 2015). 
Oleh karena itu pendidikan untuk mencegah obesitas sangat diperlukan selain untuk menghindari terhindari dari penyakit dan untuk membuat tubuh menjadi lebih sehat.

\section{MASALAH}

Obesitas merupakan penyebab tingginya angka morbiditas dan mortalitas di dunia. Obesitas banyak dialami oleh wanita usia subur karena pola makan yang tidak seimbang sehingga menyebabkan status gizi seseorang berlebihan. Obesitas abdominal pada wanita lebih tinggi (44,3\%) dari pada pria (4,7\%) (Riskesdas, 2018). Kelebihan obesitas sampai saat ini masih menjadi masalah kesehatan di seluruh dunia, termasuk Indonesia oleh sebab itu perlu adanya pendidikan untuk pencegahan obesitas.

Di desa Jatikalang Kec. Prambon masih rendahnya pendidikan tentang pencegahan obesitas pada ibu - ibu, dan hampir tidak pernah di posyandu Desa Jatikalang memberikan pendidikan pencegahan obesitas, oleh karena itu target dalam kegiatan ini adalah memberikan pemeriksaan dan pemberian pendidikan kesehatan pada ibu di Posyandu Desa Jatikalang - Sidoarjo.

Berdasarkan hal tersebut di atas, diadakanlah kegiatan pendidikan pencegahan obesitas pada ibu - ibu di posyandu Desa Jatikalang pada tanggal 18 Juni 2019. Selain itu kegiatan ini merupakan kegiatan rutin pengabdian kepada masyarakat sesuai dengan agenda LPPM Universitas Muhammadiyah Gresik guna meningkatkan minat dan kesadaran masyarakat tentang pentingnya pendidikan pencegahan obesitas dengan melibatkan mahasiswa DIV Kebidanan.

\section{METODE}

Kegiatan ini dilakukan pada hari selasa, tanggal 18 juni 2019 di posyandu Desa Jatilakang Kecamatan Prambon Kabupaten Sidoarjo. Sarana yang dibutuhkan pada saat melakukan kegiatan ini antara lain sentral ruangan terbuka, meja, tempat duduk periksa, alat timbang badan, tensimeter, metlin (alat ukur lingkar perut), lembar pendaftaran, lembar pemeriksaan, alat tulis, leaflet / lembar balik tentang obesitas. 
Metode yang digunakan dalam kegiatan ini adalah dengan pasien atau ibu terlebih dahulu diukur berat badan, kemudian pengukur lingkar dada dan lingkar perut, Selanjutnya memberikan pendidikan kepada ibu pencegahan obesitas yaitu memantau berat badan setiap bulan, memberikan penyuluhan tentang obesitas, dan memberikan tips cara mencegah obesitas. Kemudian memberikan edukasi kepada kader tentang pentingnya pemeriksaan obesitas setiap bulan, memberikan penyuluhan obesitas, dan memberikan tips tentang obesitas. Setelah selesai, kader dengan didampingi oleh pemeriksa melakukan pencatatan dan pelaporan status kesehatan ibu di Desa Jatikalang Kec. Prambon Kab. Sidoarjo.

\section{HASIL DAN PEMBAHASAN}

Pendidikan Pencegahan Obesitas dilakukan di Posyandu pada hari Selasa 18 Juni 2019 mulai pukul 08.00 - 12.00 WIB. Acara tersebut dilaksanakan di Desa Jatikalang Prambon - Sidoarjo. Peserta yang hadir yaitu 86 ibu ( 78 ibu - ibu peserta yang hadir, dan 8 ibu - ibu kader ).

Pelaksanaan kegiatan ini berjalan dengan lancar dengan hasil sebanyak $38 \mathrm{ibu}$ dengan status berat badan normal dan 40 ibu kelebihan berat badan. Kemudian semua ibu - ibu diberikan edukasi tentang penyebap obesitas, bahaya obesitas bagi kesehatan, tips mencegah obesitas. Ibu - Ibu juga diberitahu bahwa setiap 2 minggu dan setiap 1 bulan sekali secara intesnsif diingatkan untuk melakukan pemeriksaan ulang secara sendiri ataupu kepada bidan desa Jatilakang, sehingga apabila terjadi kelebihan berat badan atau obesitas maka bisa segera dideteksi secara dini dan dilakukan penanganan segera. Setelah seluruh ibu mendapatkan pendidikan pencegahan obesitas, kader dengan didampingi oleh pemeriksa (tim peneliti) melakukan pencatatan dan pelaporan mengenai status perkembangan ibu yang datang ke Posyandu Desa Jatikalang Kec. Prambon Kab. Sidoarjo, dan memberikan edukasi kepada kader untuk terus memberikan motivasi kepada ibu agar terus mencegah obesitas agar dapat hidup sehat

Setelah mendapat pengetahuan akan pendidikan dan pencegahan obesitas pada ibu - ibu di Desa Jatikalang Kec. Prambon hasil didapatkan pengetahuan ibu baik dan ibu - ibu memahami hasil penjelasan yang diberikan. Dibuktikan dengan adanya hasil pemantauan di bulan berikutnya terhadap pemantauan berat badan 
bahwa ibu - ibu dari 40 yang mengalami berat badan berlebih menurun menjadi 37 $\mathrm{ibu}-\mathrm{ibu}$.

\section{KESIMPULAN}

Kegiatan pendidikan pencegahan obesitas ini telah berjalan lancar. Pendidikan pencegahan obesitas ini perlu diberikan untuk ibu - ibu agar menjaga kesehatan dan untuk mencegah penyakit lebih lanjut, dan dapat dilakukan penanganan segera. Pemetaan dan pelaporan status perkembangan status ibu di Posyandu Desa Jatikalang Kec. Prambon Kabupaten Sidoarjo dilakukan oleh tim pengabdian masyarakat prodi D - IV Kebidanan Universitas Muhammadiyah Gresik dan kader posyandu desa Jatikalang.

Status pemeriksaan ibu di Posyandu Desa Jatikalang Kec. Prambon Kabupaten Sidoarjo didapatkan sebagai berikut: sebanyak 38 ibu (26.72\%) dengan status berat badan normal, sebanyak 40 ibu mengalami (51.28 \%) status kelebihan berat badan atau obesitas

Hasil dari pendidikan pencegahan obesitas ini ibu paham akan penjelasan atau edukasi yang diberikan oleh pembicara dan ibu - ibu bersedia melakukan tips untuk pencegahan obesitas agara badan menjadi sehat dan terhindar dari penyakit, dan dibuktikan dengan adanya hasil pemantauan di bulan berikutnya terhadap pemantauan berat badan bahwa ibu - ibu dari 40 yang mengalami berat badan berlebih menurun menjadi $37 \mathrm{ibu}$ - ibu.

\section{DAFTAR PUSTAKA}

Ali M. (2009). Pendidikan untuk Pembangunan Nasional. Bandung: INTIMA

Siregar, Afriyana. 2012. Handout Patologi Manusia Dasar.; Poltekkes Kemenkes Bengkulu.

Hernomo, Kusumobroto. 2006. Ilmu penyakit dalam., 2006 Jakarta ; Jakarta ILMU PENYAKIT DALAM, DR.Dr. Soeparman.

Soepaman, Sarwono Waspadji. 2001. Ilmu Penyakit dalam Jilid II Edisi 3. Jakarta : Balai Penerbit FKUI

Tangel, Finka.2013. Penatalaksanaan obesitas. Jakarta. medstudent.blogspot 
Budiyanto.2002. Penatalaksaan diet penderita obesitas. Universitas Negeri Yogyakarta (UNY)

https://www.ui.ac.id/berita/perilaku-gaya-hidup-sehat-kurangi-potensi-obesitaspada-anak-dan-remaja.html

http://www.depkes.go.id/resources/download/infoterkini/materi_rakorpop_2018/ Hasil\%20Riskesdas\%202018.pdf

Maidartati dan Parsaulian P. (2015). Gambaran Pengetahuan Ibu Hamil Trimester I tentang Pengaruh Rokok terhadap Tumbuh Kembang Janin di Polikandungan RSUD Kota Bandung. Jurnal Ilmu Keperawatan, III (1). 